\title{
Article
}

\section{Kicking off: Is the association between the FIFA world cup and domestic abuse an international phenomenon?}

Kirby, Stuart and Birdsall, Nathan

Available at http://clok.uclan.ac.uk/37433/

Kirby, Stuart and Birdsall, Nathan ORCID: 0000-0002-7253-9211 (2021)

Kicking off: Is the association between the FIFA world cup and domestic abuse an international phenomenon? The Police Journal: Theory, Practice and Principles . ISSN 0032-258X

It is advisable to refer to the publisher's version if you intend to cite from the work. http://dx.doi.org/10.1177/0032258X211007182

For more information about UCLan's research in this area go to http://www.uclan.ac.uk/researchgroups/ and search for <name of research Group>.

For information about Research generally at UCLan please go to http://www.uclan.ac.uk/research/

All outputs in CLoK are protected by Intellectual Property Rights law, including Copyright law. Copyright, IPR and Moral Rights for the works on this site are retained by the individual authors and/or other copyright owners. Terms and conditions for use of this material are defined in the policies page.

\section{CLoK}

Central Lancashire online Knowledge www.clok.uclan.ac.uk

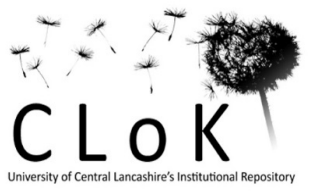


Kicking off: Is the association between the FIFA world cup and domestic abuse an international phenomenon?

\section{Abstract}

This study examines whether increases in incidents of female domestic abuse occur during FIFA world cup tournaments, in countries, other than the UK. Columbian medical records providing national daily counts, relating to Violence Against Women (VAW) and females subject to Intimate Partner Violence (IPV), across two world cup tournaments (2014/2018) were analysed. The number of medical examinations rose by $43 \%$ (VAW) and $39 \%$ (IPV) during the 2014 Columbia match days, and 26\% (VAW) and 27\% (IPV) during the 2018 match days, when compared to non-match days $(p<.001)$. The increases were higher on a weekend and when winning, rather than losing.

\section{Introduction}

Eradicating domestic abuse is a priority for many governments and focuses the attention of numerous academics, law enforcement and victim support groups. Whilst much of the research emphasises individual and socio-structural accounts (Robinson, 2010), this study looks at how situational factors (specifically the FIFA football world cup tournament), can be linked with domestic abuse even when it occurs outside the host nation. To explore this question the study initially considers the range of positive and negative outcomes generated through the exponential global growth of football. It then focuses on the link between domestic abuse and football, which Kirby et al. (2013), have previously shown to be present in the UK across three FIFA football world cup tournaments. It investigates whether the same phenomenon can be observed in another country and continent, through examining 
the number of female medical records for violence in Columbia, across two world cup competitions. The study also questions the level of responsibility that football's governing bodies (and financial beneficiaries) have for unintended consequences, even when these occur outside the tournament location.

\section{Literature Review}

Beck (1992) postulated that modernisation can create new hazards to the security of society. Felson (2002) supports this with Routine Activity Theory, explaining the opportunities for crime and disorder emerge from the natural rhythms of everyday life. This can be seen with football which, since the $13^{\text {th }}$ Century, has been associated with violence (Carnibella et al.,1996), explained through the aggressive competition between teams, players and supporters, which generates both winners and losers (Swain, 2000: 103). The theory can also explain increases in domestic abuse, when intimate, but acrimonious, partners are compelled to spend more time with each other, in the absence of a capable guardian. Indeed, the United Nations reported a $20 \%$ international increase of domestic abuse during the coronavirus lockdown, as victims were required to spend more time with their abuser (Mohan, 2020). Domestic abuse is also reported more frequently on weekends (Gantz et al. 2006; Vazquez et al. 2005); holidays, and exceptionally hot days (Card \& Dahl, 2011).

This study continues to examine the relationship between domestic abuse and the FIFA football world cup tournament. Occurring every four years, for a four-week period between June and July, involving 32 teams and 48 games, the competition is the world's largest sporting event and epitomises the global rise of football consumerism. During the 2018 
tournament it was watched by approximately 3.6 million people, either at home, at communal facilities or on digital platforms (FIFA, 2018a). The event leads to both benefits and unintended consequences. The most obvious benefit is financial, with the 2014 Brazilian tournament said to increase the world economy between $\$ 3$ to $\$ 14$ billion (Rossington, 2018). However, some of this revenue is associated with betting, of which football is estimated to account for $70 \%$ of a $\$ 100$ billion global business (Keogh \& Rose, 2013). Further, as this business is supported by an aggressive advertising sector, it has been linked to a rise in problem gamblers (Alli et al., 2018; Football report, 2019). Unfortunately, other unintended consequences associated with the tournament also exist. $f 500$ million ( $\$ 661$ million), was thought to be lost in the UK through employees reporting sick after an England quarterfinal game, a trend which was thought to be replicated in other nations (Rossington, 2018). A further concern is the increase in general violence, which is reported across a variety of countries during the tournament period (Quigg et al. 2012; Salazar, 2018). This trend extends to domestic abuse, with Kirby et al. (2013) showing a rise of such incidents within the UK, across three separate world cup tournaments $(2002,2006,2010)$. In fact, the risk of domestic abuse rose by $26 \%$ following a win or draw, and a $38 \%$ increase when the team lost. The association between domestic abuse and football has also been established at a local level in the UK, when close rivals played high-profile games in Scotland (Williams et al., 2013; Williams \& Neville 2014).

Establishing whether events and situations facilitate an increase in crime is important as efforts can be made to alter the situation and mitigate the impact. As an example, Rational Choice Theory (Cornish \& Clarke, 1976) illustrates that crimes can be reduced by affecting the balance between risk and reward in the mind of the offender. This can be facilitated by 
increasing the effort needed to commit the offence, increasing the risk of detection, reducing the rewards associated with the offence, removing any excuses surrounding the offending and reducing any provocation that motivates the offender. Following the wellpublicised findings by Kirby et al. (2013), numerous UK police agencies and victim groups used the research to increase publicity through the 'not-so-beautiful game' campaign (NCDV, 2018). The campaign gained international attention (Sullivan, 2018) as it aimed to increase awareness of the link between football and abuse, demotivate offenders, and increase police resources on match days to improve detection and general response. Whilst the campaign gained international traction due to its aims, the link between football and domestic abuse remains unclear in other countries who compete in the tournament. However, as football is a global phenomenon (Giulianotti \& Robertson, 2009), it is possible that the link between the world cup tournament and domestic abuse extends to other countries outside of the UK.

To examine this phenomenon the article scrutinises Columbia, South America. The finding that violence occurs far away from stadia on match days has already been established in South America. In Costa Rica, during the 2014 world cup tournament, there was an increase in general violence, with emergency calls increasing by up to $45 \%$. Similarly, the government Health Observatory in Bogotá, Columbia discovered treatment for heart attacks increased by $54 \%$, whilst the homicide rate in Cali, Colombia, also rose during football match days when compared to non-match days (Sanchez et al., 2013). In fact, this level of general violence was highlighted during the 1980 s, by Colombian drug clans who took control of domestic league soccer teams, eventually leading to the murder of a referee in 1989 and the assassination of a defender who was unfortunate to score an own goal in the 1994 
World Cup (Cardenas, 2013). It is evident that football is part of the national identity in Columbia. An estimated $80 \%$ of the Columbian population are thought to watch the FIFA tournament, which is more than the number of eligible voters who voted in the presidential elections (Salazar, 2018). Indeed, whilst three-quarters of offices provided their employees with TVs to watch the games, it was reported that workplace absences increased by over 40\% (Salazar, 2018). The academic, Andrés Dávila, explains social norms are relaxed during football games by encouraging the drinking of alcohol and tolerance towards shouting and swearing (Sanchez et al., 2011). It is also important to note that outside of football, Columbia is reported to suffer from high levels of gender inequality and institutionalised violence (Rosen \& Marklund, 2015), with one of the highest rates of physical IPV in the world (Friedemann-Sanchez \& Lovaton, 2012). In fact a 2014 poll of Columbian government officials found that over half believed domestic abuse should be resolved privately and $11 \%$ thought that a partner's abuse should be forgiven if they were drunk (Bradshaw-Smith, 2015).

This article therefore examines whether the FIFA world cup can be associated with increased rates of domestic abuse in Columbia during match days. The previous UK study, as well as this Columbian study, simply count the number of individuals who ask for assistance during the tournament period. Whilst the UK study used police reports of domestic abuse across a specific region (which can encompass diverse behaviours leading to harassment, threats, and injury), this Columbian study uses national data relating to violence requiring hospital treatment. Therefore, whilst neither study specifically questions the victim about the relationship between the abuse and the tournament, they both serve to monitor 
whether significant increases in intimate partner aggression occur during the period of the world cup tournament.

\section{METHODOLOGY}

\section{Study Design}

The methodology was based on a secondary source design, using Columbian national figures relating to Violence against Women (VAW), between $11^{\text {th }}$ June $-10^{\text {th }}$ July across the years 2014 to 2018. The data was provided by the National Institute of Legal Medicine and Forensic Sciences (Instituto Nacional de Medicina Legal y Ciencias Forenses) who returned daily counts of individuals who received medical examinations for: homicides of women; alleged sex crime against women; violence against girls and adolescents; violence against older women; violence within a couple against women; and, violence among other relatives against women. Further, there have been global efforts for health services to identify Intimate Partner Violence (IPV) more accurately, to assist in improving the response and reduce the harm (WHO 2013, NICE 2014). As a result, a subset of this dataset (violence within a couple against women) was identified as IPV due to the certainty from guidance notes that this form of violence against women referred specifically to an intimate partnership. This was in contrast to other categories which involved violence from strangers and family members. However, as emphasised by Olive (2016), more still needs to be done in the identification of IPV, which makes this category of violence more likely to be underreported. Being able to use both offence categories (VAW and IPV) assists in establishing whether there are any underlying trends associated with the tournament. The national data was completely anonymised, with no further information on variables such as 
the age range or repeat victimisation. All count data was included in the study, imported and coded within IBM SPSS v25.

As with previous literature (Kirby et al., 2013), the focus of the study was to analyse the relationship of the count data across match days in comparison to non-match days The data allowed the analysis of Columbia national team games for the World Cup tournaments played in Brazil (2014) and Russia (2018). As no games were drawn, three levels were coded: non-match day (0); World Cup match loss (1) and World Cup match win (2). The coding covered football matches over the following dates:

2014 World Cup (Brazil).

14th June 2014: Colombia (3) v Greece (0) - Win 19th June 2014: Colombia (2) v Ivory Coast (1) - Win 24th June 2014: Colombia (4) v Japan (1) - Win 28th June 2014: Colombia (2) v Uruguay (0) - Win 4th July 2014: Colombia (1) v Brazil (2) - Loss 2018 World Cup (Russia) 19th June 2018: Colombia (1) v Japan (2) - Loss 24th June 2018: Colombia (3) v Poland (0) - Win 28th June 2018: Colombia (1) v Senegal (0) - Win 3rd July 2018: Colombia (1) (3) v England (1) (4) - Loss 
Daily counts were collated for the sample period each year, resulting in a total of 150 days of data (30 days for each of the five years). The first sample related to VAW, defined as: 'any act of gender-based violence that results in, or is likely to result in, physical, sexual, or mental harm or suffering to women, including threats of such acts, coercion or arbitrary deprivation of liberty, whether occurring in public or in private life.' (United Nations, 1993; cited in WHO, 2017).

The incidents ranged between 41 cases (Saturday 30 th June 2018) and 707 cases (Sunday $24^{\text {th }}$ June 2018$)$, with the mean average being $331.00(S D=87.74)$.

The second sample comprised incidents of IPV, defined as:

'behaviour by an intimate partner or ex-partner that causes physical, sexual or psychological harm, including physical aggression, sexual coercion, psychological abuse and controlling behaviours.' (WHO, 2017).

Because IPV is a subsection of VAW, it was drawn from the VAW sample and again relates only to female victims. Incidents ranged between 12 (Saturday $30^{\text {th }}$ June 2018) and 274 (Sunday $24^{\text {th }}$ June 2018). Overall, the mean average number of medical exams for IPV was $117.79(S D=45.84)$.

Analysis

Descriptive statistics were conducted and supplemented by inferential analysis. The data did not meet the assumptions for a One-Sample Kolmogorov-Smirnov test for Poisson distribution available in SPSS. This was due to the test requiring continuous data, whereas the current dataset concerned discrete count data (Dimitrova et al., 2017). Therefore, the 
inferential analysis first considered Poisson regression; however, MacDonald and Lattimore (2010) explain that criminological data rarely conforms to this distribution and negative binomial regressions may be more appropriate. As such, the Poisson modelling was followed by modelling using a main effects negative binomial regression with log link. As SPSS does not estimate the dispersion parameter by default, Maximum Likelihood Estimation (MLE) was specified when modelling with negative binomial regression. All modelling concerned the use of three explanatory variables: year (five levels); day of the week (seven levels); and, match days (three levels). The categories were organised in descending order, meaning the reference category was 2014 for year, Monday for day of the week, and non-match day for the match days. The models were compared using the Pearson's goodness of fit, as well as guidance from both the Akaike Information Criteria (AIC) and Bayesian Information Criteria (BIC) (Burnham \& Anderson, 2004), to determine which model fitted best and explained the data.

The analysis found that the negative binomial (MLE) models provided a better fit of both datasets than Poisson regression. The first negative binomial model related to Violence Against Women and consisted of three explanatory variables. This yielded a statistically significantly model that was a better fit of the data than the intercept only (null) model, $G^{2}(12)=137.885, p<.001$ (see Table 1 ). The second negative binomial regression examined Intimate Partner Violence and used the same three explanatory variables as the first model. This also provided a significantly better fit of the data than the intercept only (null) model, $G^{2}(12)=207.995, p<.001$ (see Table 2). 


\section{RESULTS}

Does domestic abuse increase on Columbia World Cup match days?

The analysis found, when controlling for year and day of the week using negative binomial regression, match days were associated with an increased number of medical exams for VAW when compared to non-match days (match wins $p<.001$ and match losses $p<.001$ ). For VAW, the match day average was $M=462.20(S D=78.11)$ medical examinations during the 2014 tournament and was $M=409.50(S D=209.68)$ medical examinations during the 2018 tournament, when compared to non-match days $(M=324.12, S D=78.98)$. This equated to a $43 \%$ rise in medical exams for VAW during the 2014 tournament, and a $26 \%$ rise in the 2018 tournament. The smaller rise of VAW exams in 2018 was an interesting finding and could be due to the fact that medical exams for VAW had been steadily decreasing since 2014, although not statistically significant $(p>.05)$. However, overall 2018 data did show a statistically significant decrease in VAW exams when compared directly with $2014(p<.001)$.

\section{INSERT TABLE 1 HERE}

The IPV data, showed a similar trend. The negative binomial regression showed a statistically significant greater number of violent crime examination cases during match days when compared to non-match days (match wins $p<.001$ and match losses $p<.001$ ). The descriptive statistical analysis illustrated that the average number of medical examinations was $M=160.00(S D=29.21)$ during 2014 Columbian match days and was $M=146.75(S D=$ 86.58) during 2018 match days, when compared with non-match days ( $M=115.48, S D=$ 
44.26). This meant a 39\% rise in IPV medical examinations for the 2014 match games and a $27 \%$ rise for 2018 tournament match days when compared with non-match days.

\section{INSERT TABLE 2 HERE}

Does winning or losing make a difference?

The descriptive analysis showed the average number of examinations for VAW were greater following a match day win $(M=457.33, S D=168.10)$ than a match day loss $(M=401.67, S D$ $=86.57)$. When analysed through the negative binomial regression this equated to a $48 \%$ increase following a win $(p<.001)$ and a 39\% increase following a match day loss $(p<.001)$. This was consistent with the prevalence of IPV exams following a match day win ( $M=$ $168.50, S D=65.51)$ compared to a match day loss $(M=125.33, S D=23.54)$. The IPV regression model illustrated how match day wins resulted in a $48 \%$ increase in medical examinations $(p<.001)$ and a $46 \%$ increase following match day losses $(p<.001)$, when both were compared to non-match days. In fact, the greatest increase in both VAW and IPV exams was on Sunday $24^{\text {th }}$ June 2018 , where Colombia beat Poland (3-0).

Does domestic abuse increase on the weekend?

There were also more requests for VAW and IPV medical treatment when Columbia played World Cup matches on the weekend than on weekdays (see Table 3). Across the 2014 and 2018 tournaments, there were three matches hosted on Tuesday, two on Thursday, a single match on Friday, two on Saturday, and a single match on Sunday. The analysis found that both VAW and IPV increased over the days of Saturday, Sunday and Monday in comparison 
to the rest of the week. The peak for both datasets was Sunday, with a $37 \%$ increase in VAW exams $(p<.001)$ and a $54 \%$ increase in IPV exams $(p<.001)$ when compared to Monday.

\section{DISCUSSION}

Domestic abuse is a pervasive problem across the world and consumes considerable effort from government, victim support groups and law enforcement agencies. These efforts normally concentrate on the individuals associated with the abuse, rather than the situations that facilitate them. However, if the situational dynamics which lead to peak periods of domestic abuse can be identified, more targeted interventions can be designed to reduce the problem, as has been described earlier.

In the UK a clear link has been made between domestic abuse and football, involving both domestic teams and the FIFA world cup tournament. Kirby et al. (2013) specifically found the UK experienced increased level of domestic abuse on England match days, across three separate FIFA world cup tournaments. This occurred even when the England team won or drew but increased further when the team lost, especially at a weekend and was highest when the team exited the tournament.

Due to the globalised nature of football it is possible that this relationship is an international phenomenon. Giulianotti and Robertson (2009) explain that football is currently in its 'millennial' phase, having risen in popularity and profitability. This transformation means people watch, celebrate (and mourn) the world's most popular game, in venues far away from the stadiums they are played. Indeed, the 2018 FIFA world cup was said to be watched by over half of the world's population, either at home, outside the home in leisure facilities 
or on digital platforms. To establish whether this relationship is replicated in another continent and country this study used national records from Columbia. This provided counts as to the number of females requiring medical assistance between 2014 and 2018, which covered the World Cup tournaments which were hosted in Brazil (2014) and Russia (2018). There are obvious limitations of the data. As with the UK study the victims were not asked to comment upon the relevance of the tournament in relation to the abuse they suffered.

The Columbian data showed similar, although not identical trends to the UK. In contrast to the UK study the Columbian research included analysis of all gender-based violence requiring hospital treatment against women (VAW), which included all types of perpetrator. The core finding of this study illustrated that both VAW and IPV medical examinations rose significantly following a Columbian World Cup game. Further, this increase was at its highest during a weekend game (Saturday to Monday), with Sunday showing the highest rise. However, it should be highlighted that the UK study used police incident data, which is likely to be more accurate in recording the time of the assault. This is in contrast to the Columbian medical exam data which is more likely to involve a slight time delay, as victims make decisions and arrangements about visiting a medical centre.

Whilst both the UK and this Columbian study show all national team match days are associated with an increase in domestic abuse and violence, perhaps the biggest anomaly was that Columbia showed a higher incidence following a win, rather than a loss. A clear understanding of why this is the case is not possible from the available data, although it is possible that further situational dynamics come into play. Whilst one may expect Columbian potential offenders to be in celebratory mood following a win, a closer inspection of media 
reporting explained the team was "under pressure" following losses in the opening matches and the "tension was palpable" (FIFA, 2018b). Further, a significant win may also be associated with increased alcohol consumption, however further qualitative research is needed to provide a more robust explanation.

Indeed, whilst it was not the purpose of this study to establish the reasons for the increase in the phenomenon a number of points are worthy of comment. This paper accepts that, in general, domestic abuse relates to a pattern of repeat behaviour rather than a single event, linked to a football game. Rather, the article argues that the tournament serves as a trigger to facilitate the likelihood of abusive acts to occur as it brings together a number of factors generally associated with domestic abuse. Williams and Neville (2014: 242) argue hegemonic masculinity, sports (which introduces competitive tension) and alcohol are the "holy trinity" in explaining the association between sports and domestic abuse. Similarly, Kirby et al. (2013) spoke about the tournament generating a perfect storm of factors. These include the conflict occurring between partners regarding TV programme scheduling, as well as the tournament being played in summer months and warmer temperatures, all of which are aligned with general or domestic violence incidents.

In conclusion, the study shows the phenomenon is not isolated to one country in Europe but can also be observed in Columbia, South America. It therefore suggests the link between domestic abuse and the FIFA world cup tournament is international and extends via the media to locations far outside the host country. The identification of this link also generates two further considerations. The first is to more accurately understand the factors that trigger intimate partner aggression during the tournament, as once these are known 
interventions can be put in place to negate them. For example, during the 2018 World Cup, England's National Centre for Domestic Violence released posters depicting a woman with blood running down and across her face in the shape of St. George's Cross, with the caption, "If England get beaten, so will she", in an effort to reduce public acceptance and remove excuses. Similarly, in 2015, Costa Rica's National Institute for Women worked with broadcasters to create an additional scoreboard when playing Haiti during a World Cup qualifying match. This displayed the number of domestic abuse calls the country's police received in real time, with the game ending Costa Rica, 1, Haiti, 0, and Violence Against Women, 31. The scoreboard seems to have had a positive effect as during Costa Rica's next qualifying match, there was almost a 33\% reduction in calls reporting IPV. The second point inquires who should pay for any future research and interventions in this matter. An ongoing debate in the UK is whether football clubs should pay more in relation to the crime and disorder that emanates from football matches, extending beyond the stadium for the period the game is played (Kurland et al., 2010; 2014; 2018). For example, the Metropolitan Police Service (UK) estimates spending $f 6.7$ million on policing matches in $2016 / 17$, with only $5.1 \%$ of this budget being met by the football club (Stott et al., 2019). This study shows football generates a much wider global impact than the venue in which it is played, and the game is governed both nationally and internationally by a variety of organisations. What level of responsibility governing bodies should have in relation to designing, co-ordinating and funding interventions to reduce this unintended harm is currently unanswered. As the game is overwhelmingly overseen by men, this may be interpreted, by some, as the reason why female victimology has not been emphasised sufficiently. 


\section{REFERENCES}

Alli R, Arden-Close E, McAlaney J and Phalp K (2018) World Cup online betting is the highest it's ever been. The Conversation. Available at: https://theconversation.com/worldcup-online-betting-is-the-highest-its-ever-been-98507 (accessed 1 May 2020).

Badenhausen K (2018) Numbers done by FIFA World Cup 2018: The money behind the biggest event In sports. Available at: https://www.forbes.com/sites/kurtbadenhausen/2018/06/14/world-cup-2018-themoney-behind-the-biggest-event-in-sports/\#537ac3c66973 (accessed 1 May 2020).

Beck U (1992) Risk society: towards a new modernity. London: Sage.

Bradshaw-Smith A (2015) More than half of Colombia officials think domestic violence 'should be solved in privacy'. Available at: https://colombiareports.com/mostcolombian-officials-say-domestic-violence-should-be-solved-in-privacy/ (accessed 21 August 2019)

Burnham K and Anderson D (2004) Multimodel inference: Understanding AIC and BIC in model selection. Sociological Methods and Research 33(2): 261-304.

Card, D. and Dahl, G. (2011), 'Family violence and football: The effect of unexpected emotional cues on violent behaviour', The Quarterly Journal of Economics, Vol. 126, pp 103143.

Cardenas A (2013) Peace building through sport? An introduction to sport for development and peace. Journal of Conflictology 4(1): 24-33.

Carnibella G, Fox A, Fox K, McCann J, Marsh J and Marsh P (1996) Football violence in Europe. Oxford: Social Issues Research Centre.

Crowley, A. Brooks, O. and Lombard, N. (2014) Football and domestic abuse: A literature review. Report No.6/2014, The Scottish Centre for Crime and Justice Research, UK. Available at: https//Football-and-Domestic-Abuse_Literature-Review_25-NOV-2014 (accessed 15 April 2020).

Dickinson A, Jennings C. and Koop, G (2012) Domestic violence and football in Glasgow: Are reference points relevant? Oxford Bulletin of Economics and Statistics 78(1):1-21. 
Dimitrova D, Kaishev V and Tan S (2017) Computing the Kolmogorov-Smirnov distribution when the underlying cdf is purely discrete, mixed or continuous. [Monograph (working paper)]. Available at: https://openaccess.city.ac.uk/id/eprint/18541/ (accessed 24 April 2020).

Felson M (2002) Crime and everyday life (3rd edn). California: Pine Forge Press.

FIFA (2018) More than half the world watched record-breaking 2018 World Cup. Available at: https://www.fifa.com/worldcup/news/more-than-half-the-world-watchedrecord-breaking-2018-world-cup (accessed 14 April 2020).

FIFA (2018b) Colombia's second-half surge sends Poland packing. Available at: https://www.fifa.com/worldcup/news/review-poland--colombia-2967752\#poland-vcolombia-group-h-2018-fifa-world-cup-russia-15 (accessed 4 May 2020).

FootballShirtCulture (2019) The FIFA World Cup. Available at: http://www.footballshirtculture.com/Football-shirt-blog/Sponsorship/ (accessed 21 August 2019).

Football report (2019) How much money is being bet on sports every year. Available at: https://afootballreport.com/blog/how-much-money-is-being-bet-on-sports-everyyear (accessed 3 April 2019).

Friedemann-Sanchez G and Lovaton R (2012) Intimate partner violence in Colombia: Who is at risk? Social Forces 91(2): 663-688.

Gantz, W., Wang, Z., and Bradley, S. (2006) 'Televised NFL Games, the Family, and Domestic Violence', Chapter 22, pp. 365- 382., in Raney, A.A. and Bryant, J., Handbook of Sport and Media, New Jersey: Lawrence Erlbaum Associates.

Giulianotti R and Robertson R (2009) Globalization and Football. London: Sage.

Keogh F and Rose G (2013) Football betting - the global industry worth millions. Available at: https://www.bbc.co.uk/sport/football/24354124 (accessed 12 February 2020).

Kirby S, Francis B and Flaherty R (2013) Can the FIFA world cup football (soccer) tournament be associated with an increase in domestic abuse? Journal of Research in Crime and Delinquency 51(3): 259-276. 
Kurland J, Johnson S and Tilley N (2010) Late weekend kick-offs at premier football matches and their possible link to increased levels of alcohol-related ASB and disorder. Report, UCL Department of Security and Crime Science, UK, July.

Kurland J, Johnson S and Tilley N (2014) Offenses around stadiums: A natural experiment on crime attraction and generation. Journal of Research in Crime and Delinquency 51(1): $5-28$.

Kurland J, Tilley N and Johnson S (2017) Football pollution: An investigation of spatial and temporal patterns of crime in and around stadia in England. Security Journal 31(10): 665-684.

MacDonald J and Lattimore P (2010) Count models in Criminology. In Piquero A and Weisburd D (eds) Handbook of Quantitative Criminology. New York: Springer, pp.683-698.

Mohan, M. (2020) Coronavirus: Domestic violence 'increases globally during lockdown. Available at https://www.bbc.co.uk/news/av/world-53014211. (Accessed 19 ${ }^{\text {th }}$ October 2020)

National Centre for Domestic Violence (2018) The not-so-beautiful game. Available at: https://www.ncdv.org.uk/the-not-so-beautiful-game/ (accessed 15 October 2020).

National Institute for Health and Care Excellence (NICE) (2014) Domestic violence and abuse: How health services, social care and the organisations they work with can respond effectively. Report, NICE, UK, February.

Olive P (2016) Classificatory multiplicity: intimate partner violence diagnosis in emergency department consultations. Journal of Clinical Nursing 26(15-16): 2229-2243.

Quigg Z, Hughes K and Bellis M (2012) Effects of the 2010 world cup football tournament on emergency department assault attendances in England. European Journal of Public Health 23(3): 383-85.

Robinson A (2010) Domestic Violence. In Brookman F, Maguire M, Pierpoint H and Bennet T (eds) Handbook on Crime. Collumpton: Willan Publishing. 
Rosen S and Marklund M (2015) Where are the men? A qualitative study of the role of men and masculinities in building a culture of peace in Colombia. MSc Thesis, Lund University, Sweden.

Rossington R (2018) What Is the real cost of the world cup? In: Finance Monthly. Available at: https://www.finance-monthly.com/2018/07/what-is-the-real-cost-of-the-worldcup/ (accessed 8 March 2020).

Salazar M (2018) Soccer and domestic violence: When the beautiful game turns ugly. The Nation, 26 September. Available at:

https://www.thenation.com/article/archive/soccer-and-domestic-violence-whenthe-beautiful-game-turns-ugly/ (accessed 9 March 2020).

Sanchez A, Villaveces A, Krafty R, Park T, Weiss H, Fabio A, Puyana J, and Gutierrez M (2011) Policies for alcohol restriction and their association with interpersonal violence: A time-series analysis of homicides in Cali, Colombia. International Journal of Epidemiology 40(4): 1037-1046.

Sanchez A, Krafty R, Puyana J and Gutierrez M (2013) Football events and their association with interpersonal violence deaths. Panamerican Journal of Trauma, Critical Care and Emergency Surgery, 2(1): 26-32.

Stott C, Pearson G and West O (2019) Enabling an evidence-based approach to policing football in the UK. Policing: A Journal of Policy and Practice (online) Available at: https://doi.org/10.1093/police/pay102 (accessed 24 April 2020).

Sullivan R (2018) 'If England get beat, so will she': Shocking campaign shows domestic violence incidents spike during world cup. Available at: https://www.news.com.au/lifestyle/real-life/news-life/if-england-gets-beaten-sowill-she-shocking-campaign-shows-domestic-violence-incidents-spike-during-worldcup/news-story/56737284a00bf789d0906b8db55b6391 (accessed 15 October 2020).

Swain J (2000) 'The money's good, the fame's good, the girls are good': The role of playground football in the construction of young boys' masculinity in a junior school. British Journal of Sociology of Education. 21(1): 95- 109. 
The Tico Times (2015) 'La Sele's' third scoreboard tracks domestic violence calls. The Tico Times, 15 November. Available at: https://ticotimes.net/2015/11/15/la-seles-thirdscoreboard-tracks-domestic-violence-calls (accessed 4 May 2020).

Vazquez, S., Stohr, M.K., and Purkiss, M. (2005) 'Intimate Partner Violence Incidence and Characteristics: Idaho NIBRS 1995-2001 Data' Criminal Justice Policy Review, 16 (March), pp 99-114.

World Health Organization (2013) Responding to intimate partner violence and sexual violence against women: WHO clinical and policy guidelines. Report, World Health Organisation, Geneva. Available at: http:// www.who.int/reproductivehealth/publi cations/violence/9789241548595/en/ (accessed 30 November 2019).

World Health Organisation (2017) Violence against women. Available at: https://www.who.int/news-room/fact-sheets/detail/violence-against-women (accessed 24 April 2020).

Williams D, Neville F, House K and Donnelly P (2013) Association between old firm football matches and reported domestic (violence) incidents in Strathclyde, Scotland. Sage Open 3(3). Available at:

https://journals.sagepub.com/doi/full/10.1177/2158244013504207 (accessed 15 October 2020).

Williams D and Neville F (2014) Sport-related domestic violence: Exploring the complex relationship between sporting events and domestic violence. In Taylor M, Pooley J and Taylor R (eds) Overcoming domestic violence: Creating a dialogue around vulnerable populations. New York: Nova Science Publishers, pp.241-257. 
TABLES

Table 1: Negative Binomial Regression of medical exams for VAW.

\begin{tabular}{|c|c|c|c|c|c|}
\hline \multirow[b]{2}{*}{$\begin{array}{l}\text { Variable and } \\
\text { Level }\end{array}$} & \multirow[b]{2}{*}{$\begin{array}{l}\text { Wald Chi } \\
\text { Square }\end{array}$} & \multirow[b]{2}{*}{$p$ value } & \multirow[b]{2}{*}{ Exp. $(\beta)$} & \multicolumn{2}{|c|}{ 95\% Confidence Interval } \\
\hline & & & & Lower & Upper \\
\hline \multicolumn{6}{|l|}{ Year } \\
\hline 2014 & & & 1.000 & & \\
\hline 2015 & .095 & .758 & .987 & .906 & 1.075 \\
\hline 2016 & .533 & .466 & .969 & .889 & 1.055 \\
\hline 2017 & 1.771 & .183 & .944 & .866 & 1.028 \\
\hline 2018 & 14.169 & $<.001$ & $.852 * * *$ & .783 & .926 \\
\hline \multicolumn{6}{|l|}{ Day of the } \\
\hline \multicolumn{6}{|l|}{ Week } \\
\hline Monday & & & 1.000 & & \\
\hline Tuesday & 6.033 & .014 & $.883^{*}$ & .799 & .975 \\
\hline Wednesday & 5.941 & .015 & $.885^{*}$ & .803 & .976 \\
\hline Thursday & 17.613 & $<.001$ & $.811^{* * *}$ & .736 & .895 \\
\hline Friday & 25.444 & $<.001$ & $.775 * * *$ & .702 & .856 \\
\hline Saturday & 2.948 & .086 & .917 & .830 & 1.012 \\
\hline Sunday & 41.399 & $<.001$ & $1.371 * * *$ & 1.245 & 1.509 \\
\hline \multicolumn{6}{|l|}{ Match Day } \\
\hline Non-Match Day & & & 1.000 & & \\
\hline Match Win & 15.448 & $<.001$ & $1.475^{* * *}$ & 1.215 & 1.791 \\
\hline Match Loss & 21.536 & $<.001$ & $1.394^{* * *}$ & 1.212 & 1.604 \\
\hline
\end{tabular}

${ }^{*} p<.05 ;{ }^{* *} p<.01 ; * * * p<.001$.

Table 2: Negative Binomial Regression of medical exams for IPV.

\begin{tabular}{|c|c|c|c|c|c|}
\hline \multirow[b]{2}{*}{$\begin{array}{l}\text { Variable and } \\
\text { Level }\end{array}$} & \multirow[b]{2}{*}{$\begin{array}{l}\text { Wald Chi } \\
\text { Square }\end{array}$} & \multirow[b]{2}{*}{$p$ value } & \multirow[b]{2}{*}{$\operatorname{Exp} .(\beta)$} & \multicolumn{2}{|c|}{ 95\% Confidence Interval } \\
\hline & & & & Lower & Upper \\
\hline \multicolumn{6}{|l|}{ Year } \\
\hline 2014 & & & 1.000 & & \\
\hline 2015 & .874 & .350 & .956 & .870 & 1.051 \\
\hline 2016 & .117 & .732 & 1.017 & .925 & 1.117 \\
\hline 2017 & 1.095 & .295 & .951 & .866 & 1.045 \\
\hline 2018 & 17.021 & $<.001$ & $.823 * * *$ & .750 & .930 \\
\hline \multicolumn{6}{|l|}{ Day of the } \\
\hline \multicolumn{6}{|l|}{ Week } \\
\hline Monday & & & 1.000 & & \\
\hline Tuesday & 25.360 & $<.001$ & $.754^{* * *}$ & .676 & .842 \\
\hline Wednesday & 33.709 & $<.001$ & $.725^{* * *}$ & .651 & .808 \\
\hline Thursday & 56.175 & $<.001$ & $.660 * * *$ & .592 & .736 \\
\hline Friday & 70.513 & $<.001$ & $.623 * * *$ & .558 & .696 \\
\hline
\end{tabular}




\begin{tabular}{llllll} 
Saturday & 3.630 & .057 & .901 & .809 & 1.003 \\
Sunday & 67.181 & $<.001$ & $1.536^{* * *}$ & 1.386 & 1.702 \\
\hline Match Day & & & & & \\
Non-Match Day & & & 1.000 & & \\
Match Win & 13.013 & $<.001$ & $1.482^{* * *}$ & 1.197 & 1.836 \\
Match Loss & 24.384 & $<.001$ & $1.464^{* * *}$ & 1.258 & 1.703 \\
\hline
\end{tabular}

Table 3: Mean average number of medical exams for VAW and IPV across each day of the week.

\begin{tabular}{lllll}
\hline $\begin{array}{l}\text { Day of } \\
\text { the } \\
\text { Week }\end{array}$ & $\begin{array}{l}\text { Total VAW } \\
M(S D)\end{array}$ & $\begin{array}{l}\text { WC Match VAW } \\
\text { M (SD) }\end{array}$ & $\begin{array}{l}\text { Total IPV } \\
\text { M (SD) }\end{array}$ & $\begin{array}{l}\text { WC Match IPV } \\
\text { M (SD) }\end{array}$ \\
\hline Mon & $337.32(27.36)$ & - & $127.91(22.81)$ & - \\
Tues & $314.10(29.00)$ & $352.33(31.34)$ & $102.33(14.49)$ & $117.00(14.00)$ \\
Wed & $301.38(35.51)$ & - & $93.76(13.24)$ & - \\
Thurs & $285.91(49.27)$ & $342.00(171.12)$ & $89.14(20.13)$ & $126.00(57.98)$ \\
Fri & $271.43(64.53)$ & $495(-)$ & $82.81(20.88)$ & $148(-)$ \\
Sat & $327.00(96.83)$ & $503(82.02)$ & $122.57(36.87)$ & $181(31.11)$ \\
Sun & $474.86(89.23)$ & $707(-)$ & $202.86(35.86)$ & $274(-)$ \\
\hline
\end{tabular}

